\title{
RESEÑA DEL LIBRO DECOLONIZING DIALECTICS, DE GEORGE CICCARIELLO-MAHER (2017). DURHAM Y LONDRES: DUKE UNIVERSITY PRESS
}

George García Quesada

Universidad de Costa Rica

george.garcia@ucr.ac.cr

En el encare decolonial se pueden observar dos linajes claramente diferenciables: el primero, emparentado con el posestructuralismo, se remonta a teóricos como Derrida y Foucault, y se puede reconocer en los abordajes de Walter Mignolo y en la mayor parte del trabajo de Santiago Castro-Gómez. El otro enfoque, heredero en varios sentidos de la filosofía latinoamericana de la liberación, sigue la tradición de Marx y de diversos autores que se han apropiado productivamente de sus teorías. En esta corriente destacan escritores como Aníbal Quijano y uno de los filósofos centrales en el libro que aquí reseñamos, Enrique Dussel.

Es desde esta última tendencia que descolonizar la dialéctica aparece como un proyecto teórico con consecuencias políticas significativas. Y, si bien dialéctica y emancipación social han mantenido una estrecha relación a partir de Hegel, su historia es, ante todo, la de sus negaciones. Sabido es que su primera gran negación fue la de Marx al "ponerla sobre sus pies"e indicar la primacía de la actividad práctica material sobre el mundo de las ideas y la cultura. A su vez, para el Lukács de Historia y conciencia de clase, el énfasis de la dialéctica debe recaer sobre la categoría de totalidad, mientras que, más adelante, la revisión de Adorno denuncia la falsa totalidad, cerrada y acabada que afirma encontrar en Hegel, quien plantea en su lugar una dialéctica negativa sin un cierre o síntesis definitiva.

Como ha argumentado Jameson (2009: 49-51), presentar la dialéctica de manera no dialéctica - al estilo de un sistema filosófico, por ejemplo - es un intento vano, pues supone fijar de un modo rígido la lógica del movimiento. 
En este sentido, pareciera no haber una actitud más dialéctica que negar la dialéctica: frente a los intentos por formalizarla y convertirla en un método estático (tal y como fue el caso con fines de propaganda en países del socialismo histórico) cuando diversas corrientes y autores recurrieron a ella para comprender sus contextos particulares y enfrentar sus respectivos problemas.

El reciente libro de Ciccariello-Maher da cuenta de una nueva negación de la dialéctica a partir de las luchas contra la colonialidad en las sociedades y culturas latinoamericanas. En un auténtico gesto dialéctico, el título del libro contiene un doble sentido, contradictorio y complementario: decolonizing dialectics puede traducirse como "descolonizando la dialéctica" tanto como "dialéctica descolonizante”. En este sentido, la constante en su argumentación es el contrapunteo entre una dialéctica que podríamos llamar tradicional (y que el autor a menudo identifica como dialéctica sin más) y otra descolonizadora cuyas características son elaboradas a lo largo del libro. La primera, nos dice (2017: 9), parte de la fragmentación y la oposición dinámica para llegar a una clausura armoniosa, y entre sus elementos esenciales se encontrarían aspectos como la teleología, el determinismo, el progreso y el clase-centrismo.

Por el contrario, cada uno de los autores centrales que aborda el libro rechaza tales elementos, y sienta las bases para una dialéctica anti-capitalista y anti-colonial. Esta toma forma gracias a una línea argumentativa desarollada en un capítulo sobre Georges Sorel, dos sobre Frantz Fanon y uno sobre Dussel, con un cierre sobre el pueblo venezolano como sujeto político.

Al retomar a Sorel, Ciccariello-Maher resalta el papel del sujeto revolucionario - la clase obrera, en su planteamiento - a la vez contra el revisionismo y contra los marxistas "ortodoxos", versiones ambas que proyectaban una evolución social inevitable, ajena a las estrategias que dicha clase pudiera elaborar de manera conciente para incidir sobre su historia. Dicho mal entendido objetivismo le quitaba a la dialéctica su carácter dinámico, al desviar la voluntad revolucionaria hacia formas de política meramente reactivas. En este sentido, la reivindicación de la barbarie, esto es, de la inconmensurabilidad cultural radical entre clases sociales de una misma sociedad (2017: 40), apuesta por la irreductibilidad de las contradicciones de clase y por tanto por la imposibilidad de que el orden capitalista incorpore a la clase obrera.

Como muestra Decolonizing Dialectics, esta posición tiene implicaciones en términos de descolonización. El énfasis de Sorel sobre el estudio de las 
condiciones sociales concretas, en lugar de las abstracciones cosificadas y la concepción etapista de la "ortodoxia", prefigura los análisis de José Carlos Mariátegui sobre el Perú. Ambos se habían conocido en persona a inicios de la década de 1920, y junto con Gramsci - otro pensador de la periferia del sistema-mundo - fue una influencia central en la formación del maestro peruano (Quijano, 1982: 70-77).

Con todo, el teórico cardinal en el libro de marras es el martiniqués Frantz Fanon, quien, como Sorel, resalta el papel de la violencia en la historia, pero no se limita al conflicto entre clases sociales, sino que, en Piel negra, máscaras blancas tematiza también la violencia más cotidiana de la colonialidad. Ciccariello-Maher presta particular atención a la asimetría ontológica en la relación de colonizador y colonizado - variante de la dialéctica hegeliana del amo y el esclavo - que sitúa al segundo, racializado, en una zona de no-ser, un estatus que ad portas imposibilita el reconocimiento del otro. Este problema, indica el autor de Decolonizing Dialectics, se proyecta como un conflicto dialéctico de nivel global al desplazar el análisis desde el tema de la raza al de la nación.

Este desplazamiento, mediatizado por la revolución en Argelia, es el que se da entre Piel negra, máscaras blancas y Los condenados de la tierra. El tercer capítulo se centra en este último libro, y explica con detalle la dialéctica fanoniana de lo nacional y lo social en los procesos de liberación de las naciones colonizadas; las potencialidades de la liberación nacional solo se realizarían de modo consecuente cuando en el proceso se llega a reemplazar el nacionalismo indiferenciado con una conciencia social y económica. Este proceso no puede ser dinamizado ni por el escaso proletariado industrial ni mucho menos por la poco dinámica burguesía local - lumpenburguesía, recordando a Gunder Frank (1971) - y a la larga haría posible una lucha global contra el orden colonial moderno. La liberación nacional, sin dejar de tener fisuras y contradicciones permitiría así alcanzar un verdadero humanismo y universalismo, que resuelve el conflicto de clases de un modo distinto al previsto para los países industriales.

El capítulo cuarto discute el aporte de Enrique Dussel al debate sobre dialéctica y otredad en el contexto latinoamericano. Allí se muestra cómo el profesor argentino-mexicano, al radicalizar la temática levinasiana de la otredad para responder a las contradicciones sociales en América Latina, la empalma de forma pertinente con el concepto de la zona del no-ser de Fanon. Así, la analéctica dusseliana, en tanto que relación entre totalidad y exterioridad, es 
resaltada por Ciccariello-Maher como un componente central de la dialéctica descolonizadora.

El capítulo final explica la dialéctica descolonizante a partir del proceso chavista en Venezuela. Es allí donde el concepto dusseliano de pueblo mejor muestra sus posibilidades emancipatorias, al articular las variables de clase, "raza” y nacionalismo antiimperialista. Además, basándose en la caracterización de Quijano sobre el capitalismo como una heterogeneidad histórico-estructural, Ciccariello-Maher argumenta que el pueblo es el sujeto político contestatario que predomina en la mayor parte de América Latina, pues en esta región coexiste una compleja red de relaciones de clase junto a otra serie de exclusiones (2017: 128). Esta categoría (que en el caso particular venezolano corresponde al chavismo como movimiento revolucionario) es, por tanto, de carácter político, no económico o sociológico.

Por ello, el escritor enfatiza la pluralidad del pueblo:

el movimiento dinámico y traslapado de estas múltiples identidades hoy en Venezuela preserva la heterogeneidad del bloque popular, la parte que en último término aspira a re-crear el todo. Este pueblo es muchas cosas a la vez: es pobre, es afro-descendiente, es indígena, es mujeres, es estudiantes; es el sector informal, los campesinos, y el lumpen, todos consolidando gradualmente lo que Dussel denomina un 'hegemón analógico', o un 'bloque social de los oprimidos' y excluidos. (2017: 146; ver Dussel, 2006, 87-94)

Este quinto capítulo logra con mérito explicar la dinámica interseccional del chavismo a partir de las teorías de Sorel, Fanon y Dussel. Es en este punto que predomina la propuesta de una dialéctica descolonizadora, y ya no una crítica a la dialéctica colonizante, como parecía imperar en los primeros capítulos. El libro no es, luego, un tratado sobre dialéctica en general, sino el desarrollo de un tipo específico de ella: una dialéctica descolonizadora. Por esto, no profundiza la discusión con otras formas de dialéctica, lo cual es evidente, ante todo, en la caracterización que Decolonizing Dialectics hace de las dialécticas de Hegel y de Marx como eurocéntricas.

Temprano en el libro, Ciccariello-Maher indica que su objetivo no es abordar la discusión sobre la dialéctica en estos dos últimos autores, pero de todos modos parte de cierta interpretación de ellos. El autor se refiere así a 
la concepción marxiana de dialéctica como si llegara a una síntesis última y armoniosa que se cumpliría al resolverse el conflicto entre burguesía y proletariado industrial; se desarrollaría de manera inexorable hacia una finalidad (un telos) preestablecida. Por el contrario,

una dialéctica descolonizada reconoce tanto la fuente histórica de su movimiento fuera de Europa en las colonias, como la brutal realidad de que para los sujetos coloniales la historia a menudo parece moverse hacia atrás más que hacia adelante, si es que se moviera del todo. (2017: 11)

Sin embargo, Hegel no excluye al azar, y en los análisis de Marx no faltan en absoluto las "constantes tensiones dialécticas, la contingencia de las luchas y la indeterminación del futuro" (2017: 11) que caracterizarían según Cicciarello-Maher a la dialéctica descolonizante. Marx, por ejemplo, indicaba en el último de su serie de artículos en el Tribune sobre la India que la liberación nacional de ese país era un camino emancipatorio posible para la clase trabajadora europea. Marx retomó este camino, en particular, en la década de 1870, cuando amplió su búsqueda de sujeto anticapitalista hacia las comunas rusas, pero su giro anticolonial se manifiesta ya en la época en que redactaba sus Grundrisse, cuando rompe con las tendencias etapistas de su filosofía, tal y como lo han demostrado Kevin Anderson (2010) y Enrique Dussel (1985).

La dialéctica colonizante que critica Cicciarello-Maher no se identifica entonces con Hegel o con Marx propiamente, sino con ciertas tradiciones de lectura de estos autores. Esa versión anti-dialéctica de la dialéctica, de hecho, circuló por el mundo como parte de la antes mencionada propaganda de los estados burocratizados del socialismo histórico, pero los métodos de Hegel y Marx, como muestra Decolonizing Dialectics, no pueden reducirse a ella. De un modo más interesante, el libro también nos permite pensar el diálogo con la dialéctica crítica europea cuyos representantes, a pesar de sus méritos teóricos y filosóficos, pueden haber permanecido en una perspectiva demasiado occidental e insuficientemente global, como ha argumentado Losurdo (2019).

La introducción de la analéctica dusseliana en la discusión sobre la dialéctica resulta por ello muy oportuna. La relación entre el capital como totalización y el afuera que busca incorporar ha sido un tema con una larga historia en el análisis de la economía política del imperialismo, desde las 
tempranas indicaciones de Marx sobre la lógica expansiva del modo de producción capitalista - su carácter de mercado mundial - que pasa por Lenin y Luxemburgo (indispensable al respecto esta última) hasta las teorías de la dependencia y del sistema-mundo. La analéctica de Dussel acierta al señalar esa relación de identidad y alteridad, en la que el afuera, lo no idéntico, es inherente a la totalidad dialéctica: un afuera es necesario para que el capital se expanda, aunque cuál afuera específico él sea (el contenido de ese afuera, el espacio-tiempo social hacia el cual se expande el capitalismo), es históricamente contingente (Dussel, 2011: 88-89) ${ }^{1}$.

Sin embargo, Dussel presenta la analéctica como un más allá de la dialéctica. Esta última se ocuparía, según él, de la totalidad, pero no de su exterioridad. Pero, como han argumentado diversos teóricos, esa dinámica de incorporación de lo no-idéntico está en el núcleo mismo de la dialéctica. $\mathrm{Al}$ respecto Dilek (1992) ha mostrado que la dialéctica no es una operación en un campo homogéneo (no es una relación de "complementarios"), sino una donde la identidad incorpora en sí misma - aunque nunca enteramente - a cierta alteridad suya entre aquello que le es diferente. Otro gran dialéctico, Adorno, mantuvo esta concepción, como puede observarse por ejemplo en su póstuma Teoría estética (cfr. 2004), al referirse a la relación entre belleza y fealdad, o entre música y ruido. En otras palabras, la propia analéctica no es independiente de la dialéctica, sino uno de sus momentos. Por ello resulta también pertinente la incorporación de Ciccariello-Maher en este libro de la analéctica dusseliana en la dialéctica descolonizante, que ejemplifica esta dinámica al referirse a las intrincadas relaciones entre exclusión y opresión en la coyuntura del Caracazo (2017: 140-142).

También es un acierto del libro el enfocar a la nación - un concepto muy problemático, en lo político y en lo analítico - como un momento de la liberación frente al colonialismo y al imperialismo, que es superado por un pueblo con conciencia social y política. El pueblo no es un conjunto abstracto de ciudadanos, sino unidad que se constituye en la lucha: se forma al diferenciarse en las condiciones concretas. Es a la vez parte y totalidad, ruptura y unidad. En este sentido, es oportuno señalar que, en la tradición de la filosofía latinoamericana de la liberación (cfr. Cerutti, 1983), el concepto de pueblo que desarrolla

1 Esta dinámica de incorporación es precisamente aquella a la cual se refiere David Harvey (2003) mediante su concepto de acumulación por desposesión. 
Cicciarello-Maher está ya de entrada atravesado por la lucha de clases. No se le opone, sino que parte de ella para pensar de modo concreto las asimetrías derivadas de la acumulación de capital en el nivel de sistema-mundo. No es, por tanto, un enfoque nacionalista más que por la forma, puesto que busca tomar y transformar al Estado en contra del imperialismo, y por ello modifica, a la vez, las relaciones sociales y el balance de poder entre clases.

Conceptualmente, en otros términos, lo popular pertenece a un nivel más concreto de las luchas de clases en el ámbito mundial; de allí que, más que de otra dialéctica, la descolonizada / descolonizante que delinea el libro es un momento necesario para el análisis concreto de la coyuntura. Es mérito del libro indicar la importancia analítica y política de este momento analéctico en la dialéctica, muchas veces dejado de lado por una izquierda demasiado esquemática, o más bien manualesca.

El libro tiende, empero, a enfocarse de modo excesivo en el Estado como ámbito de acción y objetivo por tomar por parte de las luchas populares, al dejar por fuera modalidades de organización que fueron fundamentales para los movimientos populares. Las internacionales obreras, por ejemplo, ayudaron a consolidar una identidad común más allá de las fronteras nacionales, a compartir experiencias de lucha y a asumir políticas coordinadamente. En tiempos de globalización, con economías y riesgos globales, posiblemente sea necesario pensar también en un pueblo global. Por otra parte, Cuba y la propia Venezuela son ejemplo de solidaridad internacionalista que va más allá de un nacionalismo excluyente.

En un sentido concomitante, cuando Decolonizing Dialectics argumenta contra la dialéctica emancipatoria de la clase trabajadora de los países del capitalismo central, deja de lado que, para esta, como para los condenados de la tierra, el antagonista sigue siendo la clase capitalista que se expande, imperialismo mediante. Las burguesías de las potencias coloniales han cometido crímenes y atropellos contra sus propias poblaciones a la vez que contra las de las colonias, si bien por mecanismos distintos. La lucha de clases no se ha suspendido en los países del capitalismo central, y este factor es básico para pensar los conflictos más allá de los límites nacionales, desde una visión global e internacionalista.

A pesar de esta limitación, que invita a pensar en una escala más amplia el tema de la liberación y de lo popular, el libro es una lectura estimulante para 
comprender las relaciones entre diversos conceptos de la filosofía política y su relación con los movimientos sociales emancipatorios. En términos políticos, señala que la ruta necesaria para cualquier movimiento popular empieza cuando se empoderan los sectores económica y geopolíticamente oprimidos. Quizá el autor estaría de acuerdo en que este es el más grande legado de la Revolución Bolivariana, y aquel que puede volver a levantarlo por sobre las falencias del proceso hasta ahora, como la imposibilidad de salir, en medio del bloqueo económico del imperialismo de los Estados Unidos, del modelo extractivista y de la consolidación de una "boli-burguesía" con intereses no siempre alineados con el pueblo.

\section{Referencias:}

Adorno, Theodor W. Teoría estética. Madrid: Akal, (2004).

Anderson, Kevin. Marx at the Margins. Chicago: University of Chicago Press, (2010).

Cerutti Guldberg, Horacio. Filosofia de la liberación latinoamericana. México: Fondo de Cultura Económica, (1983).

Dussel, Enrique. Filosofía de la liberación. México: Fondo de Cultura Económica, (2011). 20 tesis de política. México: Siglo XXI, (2006).

La producción teórica de Marx: un comentario a los Grundrisse. México: Siglo XXI, (1985).

Frank, André Gunder. Lumpenburguesía: lumpendesarrollo. México: Era, (1971).

Harvey, David. The New Imperialism. Oxford: Oxford University Press, (2003).

Jameson, Fredric. Valences of the Dialectic. Durham: Duke University Press, (2009).

Losurdo, Domenico. El marxismo occidental. Cómo nació, cómo murió y cómo puede resucitar. Madrid: Trotta, (2019).

Quijano, Aníbal. Introducción a Mariátegui. México: Era, (1982).

Žižek, Slavoj. El sublime objeto de la ideología. México: Siglo XXI, (1992). 